\title{
Portable Weather System for Measure and Monitoring Temperature, Relative Humidity, and Pressure, Based on Bluetooth Communication
}

\author{
Edgar Manuel Cano Cruz, Juan Gabriel Ruiz Ruiz \\ Department of Computer Science, University of the Istmo, Ixtepec, Mexico
}

Email address:

ie.edgarcano@gmail.com (E. M. C. Cruz)

\section{To cite this article:}

Edgar Manuel Cano Cruz, Juan Gabriel Ruiz Ruiz. Portable Weather System for Measure and Monitoring Temperature, Relative Humidity, and Pressure, Based on Bluetooth Communication. American Journal of Networks and Communications. Vol. 4, No. 3, 2015 , pp. $49-53$. doi: 10.11648/j.ajnc.20150403.15

\begin{abstract}
The system also proposes a wireless connectivity by using the Bluetooth communication standard providing of a reliable, portable and a low-cost tool for industry where it is necessary to have an environmental control to carry out critical processes. The weather system consist of an embedded system to the development of multimedia applications based on the PIC32 microcontroller, and development is performed using the SPIES methodology for the construct embedded systems. In this paper the design of a portable system that allows monitoring of four climatic variables (temperature, relative humidity, pressure and altitude). The purpose of the system is to serve as an auxiliary tool to make decisions subsystems for environmental control in different areas.
\end{abstract}

Keywords: Embedded System, Bluetooth, Weather System, Sensors

\section{Introduction}

At present, the monitoring of climate variables such as temperature, relative humidity, atmospheric pressure and altitude are of great importance [1], because in places like farms, greenhouses, computer centers and hospitals is needed monitoring systems that allow better control of environmental conditions. The main activities of the Mexican Meteorological Service (SMN) are the acquisition, processing and diffusion of weather data at local and national levels. SMN has 188 surface automatic weather stations (surface AWS) installed throughout Mexico and 10 installed in Oaxaca state (see Figure 1).

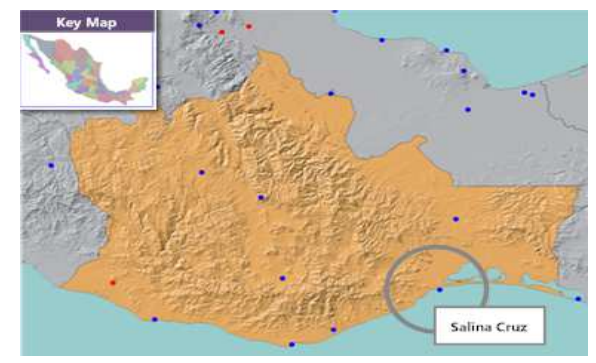

Figure 1. Surface automatic.
The AWS station is composed of sensors to receive and send weather information from where they are installed (see Figure 2).

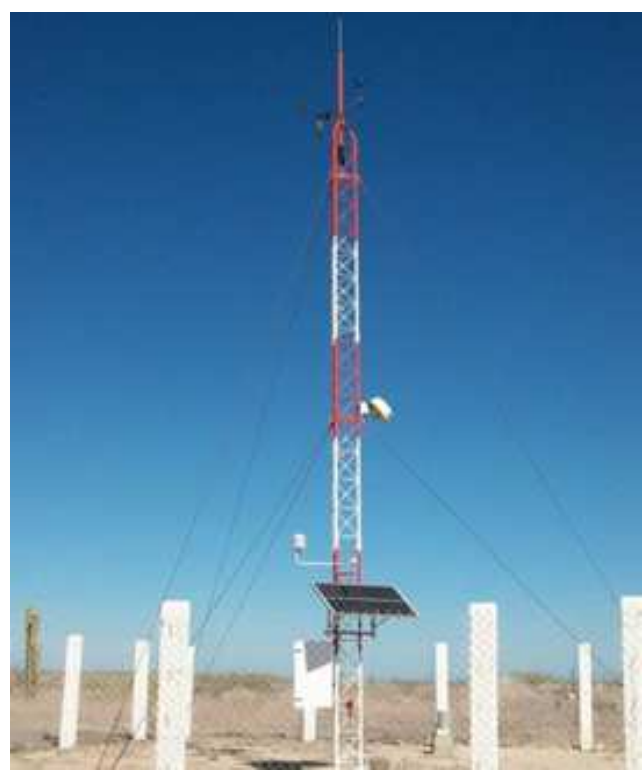

Figure 2. Surface automatic weather station. 
The sensors can meassure parameters such as: Wind direction, wind direction burst, wind speed, wind speed burst, average ambient temperature, relative humidity, atmospheric pressure, precipitation y radiation.

However, one of the main shortcomings with surface and synoptic AWS stations is that their radio action is limited to only $5 \mathrm{~km}$ on flat terrain. Also, there is no official reference for areas or zones they do not cover. Therefore, other alternatives to weather stations are necessary for the acquisition of meteorological variables [6]. Additional complications with these stations are related to the availability of information provided by sensors towards the monitoring stations. The stations usually have technical complications, for example, in the SMN list of stations [13], 26 out of 188 surface AWS are out of operation. At the time of this research, SMN had only one surface AWS station out of operation, which was located in Coatzacoalcos, Veracruz [8]. Moreover, most of the weather stations described here are not low-cost and need special facilities. Their cost ranges from $\$ 25,000$ USD to $\$ 35,000$ USD [12].

This paper proposes the design and development of a weather which is embedded, flexible, and mobile with wireless capacity and an easy-to-install system. Trying to successfully accomplish all these project requirements is challenging research.

This paper is organized as follows. The second section provides a background of projects that focus on measuring weather variables and the motivation of our research. The third section summarizes the design and development of the system proposes. The fourth section presents our results. Finally, the fifth and sixth sections present the discussion and conclusions of the research, respectively.

\section{Related Work}

There are several projects that focus on the measuring of temperature and relative humidity to control the automatization of industrial processes. In "Monitoring System of Humidity and Temperature in Biological Collections by using Free Software Tools", Vargas [15] presents a system for the automation of the preventive maintenance of biological collections using the low-cost sensor TEMPerHUM and connecting the system to a database via an Ethernet connection. Similarly, "Control System of Humidity and Temperature for Greenhouses" [3] presents some ways to accurately control humidity, temperature, lighting, ventilation and other relevant variables of greenhouses. This work develops a control system based on an SHT11 sensor with actuator and control modules. Communication between modules is transmitted wirelessly by using a transceiver operating at $2.4 \mathrm{GHz}$. PIC Microcontrollers of 16F8xx and 18F4xx series made by Microchip are used in all modules.

Another example is "Automatic Control of Agricultural Irrigation with Capacitive Sensors of Soil Moisture. Applications in Grapevine and Olive" [11] which describes the features of a capacitive humidity sensor of soils developed in the Institute of Automation (INAUT), where an automatic irrigation closed-loop control was developed.

The control system acts on the pump and irrigation valves. It identifies when it is appropriate to irrigate and how long the irrigation should last.

Another drawback is that only the manufacturer distributes all the hardware components. Updates to the system are not easy to carry out and most of them are arbitrary. A very convenient point is related to the easy setup and installation of these kinds of systems. Indeed no installation server is required.

Unlike the aforementioned research, this paper proposes a system to measure the average temperature and relative humidity with wireless communication capacity under the Bluetooth standard. It is built with an electronic board for the development of embedded multimedia systems with a touch screen to take measurements in various sites.

The proposed system is highly flexible and open to further expansion.

\section{Design and Development Portable Weather System}

The weather system was implemented with the help of the methodology for the development of embedded systems SPIES, which is detailed in [17]. SPIES uses the Unified Modeling Language (UML) to represent the phases that make up the methodology with an iterative top-down approach. It ensures that the system is tested at each phase and not only at the end. Hence, the system improves continuously over time (see Figure 3).

SPIES is extracted from process areas and specific practices in CMMI-DEV v1.2 level 2 [16], which are simplified for embedded software demands.

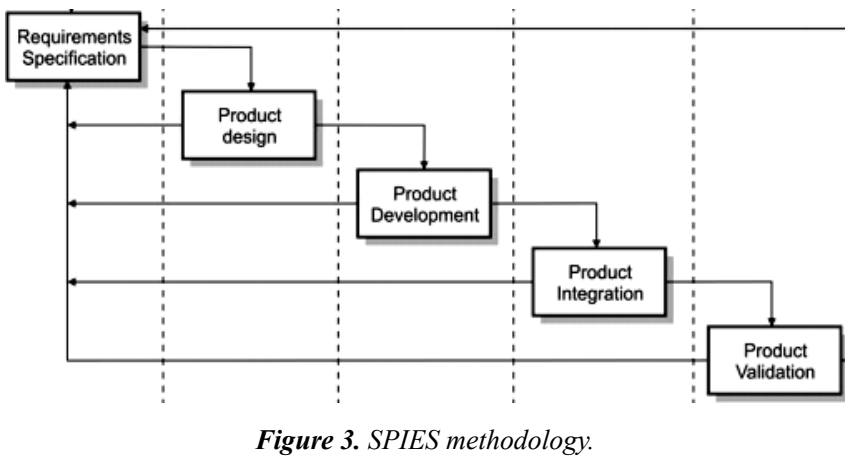

\subsection{Requirements Specification}

The weather system is divided in three subsystems: main control, weather measure control, and Bluetooth controller (at the level of electronic components) and two communication interfaces: GUI Touch and Serial Interface. Table 1 describes each module of our proposed system. 
Table 1. Modules of the system.

\begin{tabular}{ll}
\hline Column1 & Column2 \\
\hline Main control & $\begin{array}{l}\text { It is responsible for initializing and prioritizing of processor tasks. } \\
\text { This module is responsible for calibrating and controlling the sensors in the system. It also computes the relative humidity, average } \\
\text { temperature, pressure, and altitude. }\end{array}$ \\
Weather control & $\begin{array}{l}\text { This subsystem is responsible for calibrating and handling Bluetooth communication. It looks for Bluetooth devices in its vicinity to } \\
\text { establish communication and data transfer } \\
\text { Bluetooth control }\end{array}$ \\
TUI control & This subsystem organize all functionalities about Graphical user interface. \\
\hline
\end{tabular}

\subsection{Product Design}

In this phase, the sensors for the product development are choose. The structure diagram of the system is depicted in Figure 4. It shows the interaction and the static functionality of the proposed system.

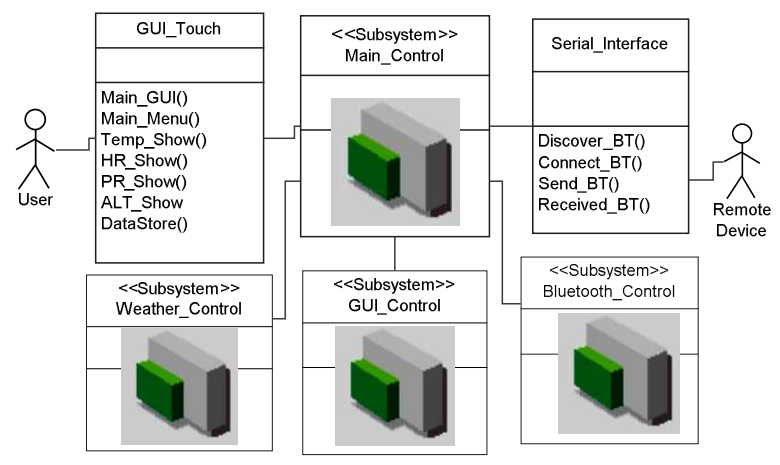

Figure 4. Structure diagram of the system proposed.

Due to the structural configuration of the system, each module can be tested individually during the system development.

The SHT11 Click sensor was selected to measure temperature and relative humidity (see Figure 5a). To measure pressure and altitude we chosen the Altitude Click sensors (see Figure $5 b$ ), both sensor of the mikroelektronika signature [9].

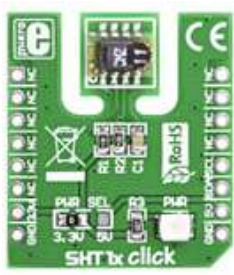

a) SHT11 click

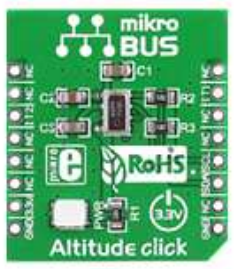

b) Altitude click
Figure 5. Senssor of the weather system.

The SHT11 Click sensor includes a digital humidity and temperature sensor SHT11. A unique capacitive sensor element is used to measure relative humidity while the temperature is measured by a band-gap sensor (SENSIRION, 2015).

The Altitude click features a MEMS pressure sensor MPL3115A2, which provides accurate pressure/altitude (20-bit). Resolution is down to $30 \mathrm{~cm}(1.5 \mathrm{~Pa})$ (freescale, 2015). The MPL3115A2 contains automatic internal data processing with data acquisition and compensation as show in Figure 6 . The MPL3115A2 sensor outputs are digitized by a high resolution 24-bit ADC.

\subsection{Product Development}

The system functionality was programmed under mikroC compiler for PIC32 microcontrollers [4] to be executed on a mikromedia card. During the assembly of the system, a rechargeable battery is connected to the rear side of the mikromedia card. The expansion card and the Bluetooth antenna are also connected.

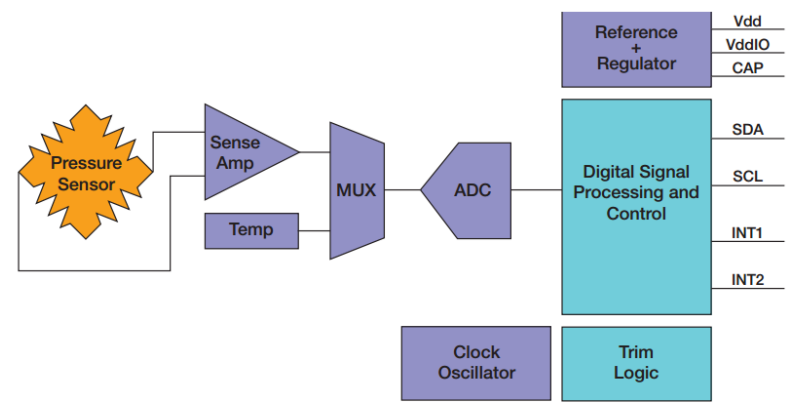

$\square$ MEMS die $\square$ Analog $\square$ Digital

Figure 6. MPL3115A2 Pressure Sensor [11].

The sensor STH11 operates under a dedicated protocol designed by SENSIRION (see Figure 7).

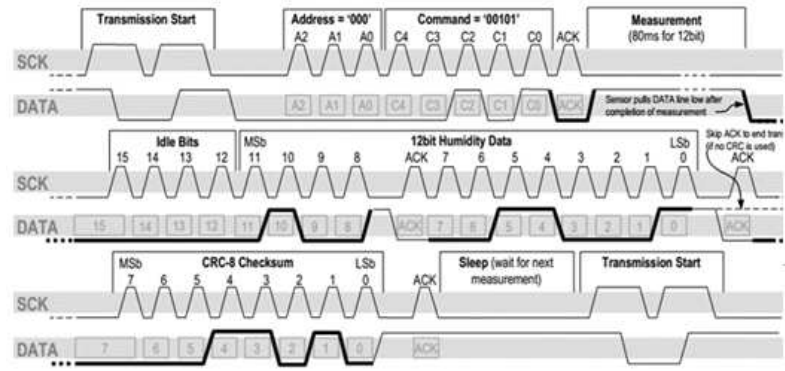

Figure 7. Sensirion protocol [10].

The bus is composed of two serial lines: serial clock input (SCK) for signal synchronization; and serial data line (DATA) for reading/writing to an SHT11 sensor. The SHT11 resolution is 14 bits for temperature and 12 bits for humidity. However, resolution can be adjusted to 12 and 8 bits respectively. In our weather system, resolutions by default were used to ensure a more accurate analog-to-digital conversion. Meanwhile, the pressure and altitude sensor MPL3115A2, the data can be 
accessed through an I2C/SPI interface making the device microcontroller; and the altitude sensor MPL3115A2. particularly suitable for direct interfacing with a

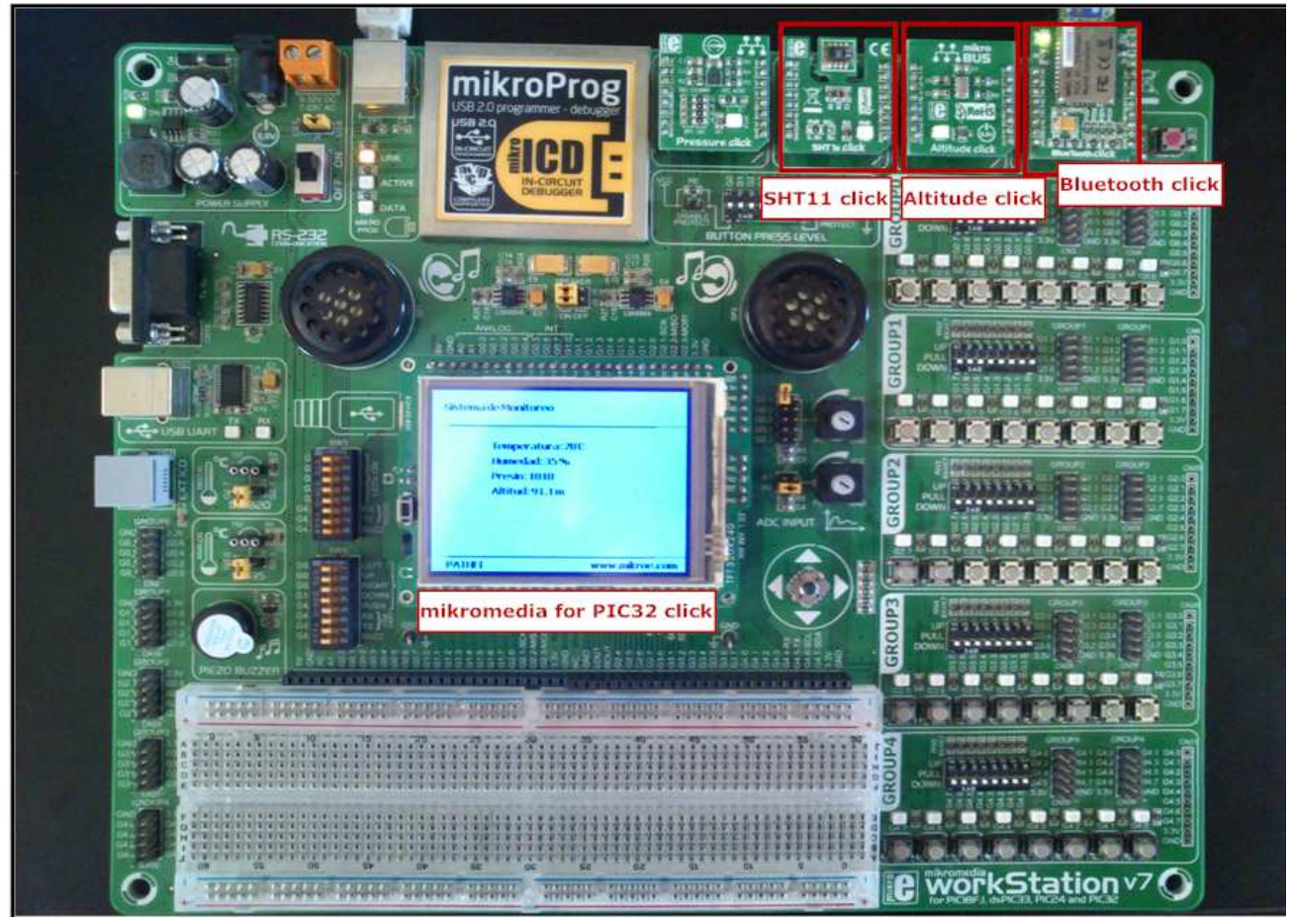

Figure 8. Weather system integration.

\subsection{Product Integration}

In the integration of the weather system a mikromedia for PIC32 card was selected (see Figure 8 and Figure 9). Mikromedia card is a compact design with different embedded peripherals for multimedia application development. The main features Mikromedia card specified in [4].

\section{Experiment Results (Product Validation)}

The system functionality was construct with the mikromedia for PIC32 on a workstation v7 under mikroC compiler for PIC32 microcontrollers [4].

During the assembly of the system, a rechargeable battery is connected to the rear side of the mikromedia card. The expansion card and the Bluetooth antenna are also connected.

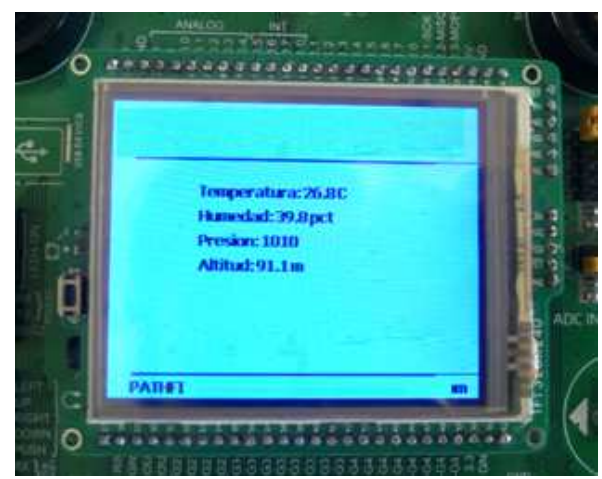

Figure 9. Weather system interface data on mikromedia.
In order to validate and compare our results and, official data from the surface AWS - SMN Salina Cruz was considered. The following weather variables were used:

- Temp. Average temperature $\left(\right.$ in ${ }^{\circ} \mathrm{C}$ ) over a 10 - minute period. Samples are taken each minute.

- $R H$. Average relative humidity (in percentage) over a 10minute period. Samples are taken each minute.

- $P B$. Average Pressure (in hectopascal) over a 10- minute period. Samples are taken each minute.

SMN website use UTC (Universal Time Coordinated), which is based in zero hour GMT (Greenwich Mean Time). In this way, equation (1) should be used to make a time conversion [5].

$$
\text { Local Time }=\mathrm{Z}+\mathrm{DZ}
$$

Table 2 shows weather variables Temp, RH and PB from the SMN webpage, taken on April 20th, 2015 from 11:00 Z hrs to 14:00 Z hrs (every 15 minutes).

The weather system was programmed in the same way to measure and store samples of temperature, relative humidity, pressure, and altitude every minute. Afterwards, an average was computed over a 10- minute period resulting in Temp, $\mathrm{RH}$, and $\mathrm{PB}$.

Every two hours, computed averages were sent by a Bluetooth connection to a PC where they were displayed and stored. Our results were very close to those found by SMN.

Correlation coefficients are: (AWS Temp, WS Temp) 0.976 $(\mathrm{p}<0.05),($ AWS RH, WS RH) $0.892(\mathrm{p}<0.05)$, and (AWS PB, WS PB) $0.927(\mathrm{p}<0.05)$. 
Table 2. Temperature (Temp), relative humidity (RH), and Pressure measures from AWS and weather system proposed (WS).

\begin{tabular}{lllllll}
\hline \multirow{2}{*}{ Time } & \multicolumn{2}{l}{ Temp $\left({ }^{\circ} \mathbf{C}\right)$} & RH $(\%)$ & \multicolumn{3}{l}{ PB (pa) } \\
\cline { 2 - 7 } & AWS & WS & AWS & WS & AWS & WS \\
\hline $11: 00$ & 23.5 & 24.2 & 27.0 & 26.2 & 98 & 99 \\
$11: 15$ & 25.8 & 26.5 & 27.1 & 26.3 & 97 & 99 \\
$11: 30$ & 21.8 & 23.4 & 27.1 & 26.3 & 96 & 99 \\
$11: 45$ & 25.8 & 27.5 & 27.0 & 26.5 & 95 & 98 \\
$12: 00$ & 26.4 & 28.6 & 26.9 & 26.6 & 91 & 95 \\
$12: 15$ & 27.5 & 28.9 & 26.9 & 26.7 & 92 & 95 \\
$12: 30$ & 26.9 & 28.4 & 26.9 & 26.7 & 94 & 97 \\
$12: 45$ & 26.4 & 28.2 & 27.0 & 26.5 & 93 & 96 \\
$13: 00$ & 26.9 & 28.5 & 27.2 & 29.0 & 92 & 95 \\
$13: 15$ & 26.4 & 28.6 & 27.4 & 29.4 & 93 & 95 \\
$13: 30$ & 26.4 & 28.4 & 27.7 & 29.5 & 92 & 94 \\
$13: 45$ & 28.1 & 30.1 & 27.8 & 29.6 & 92 & 94 \\
$14: 00$ & 29.8 & 31.2 & 28.0 & 30.0 & 89 & 94 \\
\hline
\end{tabular}

\section{Conclusions}

This paper proposes the development of a portable weather system to measure relative humidity, temperature, pressure and altitude. Its importance is that it provides a reliable and practical tool to measure temperature with a very simple device. The core component of the system, the SHT11 sensor and Pressure click, measures variables whereas Bluetooth click device establishes the communication between weather and a personal computer where this parameters are displayed and stored. A strength of this kind of system is that its installation and implementation are quick and simple because server installation is not needed.

In future research, we hope to develop the weather system by using the ARDUINO UNO card to replace the current mikromedia card, as mentioned and lower the cost of our system. We should also consider the design of a protective case for outdoor use of the device without any problems, decreasing the risks of it malfunctioning. In the very near future, a webpage could also be built in order to display the weather system data in a real-time graphical interface. Replacing the Bluetooth communication by Wi-Fi is also under consideration in order to transfer data to a cloud.

\section{References}

[1] Official webpage of humidity and temperature sensors APC (2011). Retrieved by 2014, from http://www.apc.com/.
[2] Official webpage of Arduino firm (2014). Retrieved by 2014, from http://arduino.cc/en/Main/arduinoBoardUno

[3] Hernández, R. Control System of Humidity and Temperature for Greenhouses (2004). Universidad Pedagógica y Tecnológica de Colombia (UPTC).

[4] Mikro Elektronika. Official webpage of Mikro Elektronika firm (2014). Retrieved by 2014, from http://www.mikroe.com/.

[5] OMM. Official webpage of World Meteorological Organization (2014). Retrieved by 2014, from http://www.wmo.int/pages/index_es.html.

[6] Prieto, R. Diagnóstico de las capacidades, fortalezas y necesidades para la observación, monitoreo, pronóstico y prevención del tiempo y el clima ante la variabilidad y el cambio climático en México (2008). INECC.

[7] SEMAR. Official webpage of Mexican Navy Secretariat (2013). Retrieved by August 2014, from http://meteorologia.semar.gob.mx/index.php.

[8] SEMAR. Information of surface automatic weather systems (AWS) in Coatzacoalcos, Veracruz (2013). Retrieved by 2014, from

http://meteorologia.semar.gob.mx/datos_emas/coatza.htm.

[9] SENSIRION. Official webpage of SHT11 device (2014). Retrieved by 2014, from http://www.sensirion.com/ en/products/humiditytemperature/ humidity-sensor-sht11/.

[10] SENSIRION. Reference manual of SHT11 sensor (2011).

[11] Shugurensky, C., \& Caprano, F. (2011). Automatic Control of Agricultural Irrigation with Capacitive Sensors of Soil Moisture. Applications in Grapevine and Olive. Institute of Automation (INAUT).

[12] SMN. Official web page of Mexican Weather Service (SMN), Mexico (2010). Retrieved by August 2014.

[13] SMN. Weather stations of Mexican Weather Service (2010) (SMN). Retrieved by 2014, from http://smn.cna.gob.mx/emas/catalogoa.html.

[14] Telemetría. Official webpage of Telemetría firm (2014). Retrieved by 2014, from http://www.telemetria.com.mx/ monitoreo-de-datacenter.html

[15] Vargas, H. Monitoring System of Humidity and Temperature in Biological Collections by using Free Software Tools (2011). Instituto Nacional de Biodiversidad.

[16] CMMI for Development (CMMI-DEV v1.2), 2006. Software Engineering Institute, Carnegie Mellon University.

[17] García, I., \& Cano, E. Designing and implementing a constructionist approach for improving the teaching-learning process in the embedded systems and wireless communications areas, 2011 Computer Applications in Engineering Education. 